\section{The relation between disease activity, vitamin $D$ levels and bone mineral density in men patients with ankylosing spondylitis}

\author{
Ihsane Hmamouchi, 1,2 Fadoua Allali, 1,2 \\ Btissam El Hamdaoui, ${ }^{1}$ Hanae Amine, ${ }^{1}$ \\ Samira Rostom, ${ }^{1}$ Redouane Abouqal, ${ }^{2}$ \\ Najia Hajjaj-Hassouni ${ }^{1,2}$ \\ 'Laboratory of Information and Research \\ on Bone Diseases (LIRPOS) and \\ 2Laboratory of Biostatistical, Clinical and \\ Epidemiological Research (LBRCE), \\ Faculty of Medicine and Pharmacy, Rabat, \\ University of Mohammed V-Souissi, \\ Morocco
}

\section{Abstract}

The aim of this study was to assess the vitamin D status in patients with ankylosing spondylitis (AS), and to investigate the relation between vitamin D levels, bone mineral density (BMD) and disease activity in men with ankylosing spondylitis. Seventy patients with AS and 140 healthy individuals were included in the study. BMD of femur and lumbar spine was measured by DXA. Serum $250 \mathrm{H}$ vitamin D, parathormone, serum calcium, Creactive protein levels of all participants were also measured. The disease activity was evaluated by Bath Ankylosing Spondylitis Disease Activity Index (BASDAI), and functional status by Bath Ankylosing Spondylitis Functional Index (BASFI). The mean 25(OH)D level was $17.5+9.7 \mathrm{ng} / \mathrm{mL}$ in AS patients and 21.9+7.7 $\mathrm{ng} / \mathrm{mL}$ in controls $(\mathrm{P}<0.001)$. In comparison with the control group, AS patients showed significantly higher CRP, and a significant reduction of vitamin D. In AS group, 62 patients (88.6\%) had Vitamin D deficiency, and 35 patients (50\%) were osteoporotic. Vitamin D was negatively correlated to BASDAI without any changes after adjustment for age, duration of disease, sunlight exposure, and total taking steroids $(\mathrm{r}=-0.32, \mathrm{P}<0.001)$.We found a high incidence of vitamin $\mathrm{D}$ deficiency in our patients. Our study suggests that vitamin D deficiency in male AS may indirectly lead to osteoporosis by causing an increase in the inflammatory activity. Monitoring vitamin D levels would be useful in order to determine the patients under osteoporosis risk.

\section{Introduction}

Ankylosing spondylitis (AS) is a chronic, systemic and inflammatory disease that characteristically involves the axial skeleton, enthesis regions, and in some patients the peripheral joints. ${ }^{1}$ Osteoporosis is a well-recognized complication of ankylosing spondylitis (AS), strongly correlated with disease activity. Several studies have shown involvement of inflammatory processes in the pathophysiological of AS-related osteoporosis..$^{2-7}$ Furthermore, various other factors, such as drug intake and decreased mobility in relation to pain and stiffness, may contribute to the development of osteoporosis in AS patients. ${ }^{8}$ In addition, recent studies on AS have suggested that alterations in vitamin D metabolism are associated with inflammatory activity and bone mineral density (BMD). ${ }^{9-13}$

In fact, vitamin D is a crucial factor in the regulation of calcium homeostasis and maintenance of skeletal health. It also plays an important role in the modulation of the immune system. The expression of vitamin D receptor, constitutively or after immune stimulation, on antigen presenting cells, dendritic cells, $\mathrm{T}$ and $\mathrm{B}$ cells, further suggests an immunoregulatory role of vitamin D. ${ }^{14-20}$ The aim of this study was to assess the vitamin D status in male patients with ankylosing spondylitis, and to investigate the relation between vitamin D levels, bone mineral density and disease activity in men with ankylosing spondylitis.

\section{Materials and Methods}

\section{Subjects}

This study was approved by the ethics committee of our hospital (El Ayachi University Hospital, Morocco) and all patients provided written informed consent to participate in this study.

Seventy men patients with the diagnosis of AS according to the Modified New York Criteria and 140 healthy individuals were included in the study as the control group. ${ }^{21}$ We decided to include only men with age less than 65 years in order to eliminate potential confounding factors on bone, such as age and menopause. No patient used alcohol. Fiftyeight patients had received intermittent nonsteroidal anti-inflammatory drugs (NSAID) in the previous 12 months. No patient was receiving glucocorticoid medication at the time of the study; only 5 patients had received such medication for a short time in the past (5-10 mg/day for 1 to 3 months during the disease duration). Eight patients were receiving infliximab.
Correspondence: Ihsane Hmamouchi, Department of Rheumatology, El Ayachi University Hospital, Salé, Morocco.

Tel. +2.126.61280297 - Fax: +2.125.37782653.

E-mail: i.hmamouchi@yahoo.fr

Key words: ankylosing spondylitis, disease activity, vitamin D, osteoporosis.

Acknowledgements: this study has been supported by the university Mohamed V Souissi, Rabat, Morocco. Biocentre laboratory in Rabat supported biochemical measures. We wish to express special thanks to its Director: Dr Mouhssine Mestassi.

Contributions: FA and NHH conceived the study and supervised its design, execution, and analysis and participated in the drafting and critical review of the manuscript. IH, FA and RA did data management and statistical analyses. All other authors' enrolled patients, participated in data acquisition and critical revision of the manuscript. IH wrote the paper with input from all investigators. All authors read and approved the final manuscript.

Conflict of interests: the authors declare no potential conflict of interests.

Received for publication: 8 September 2011.

Revision received: 6 August 2012.

Accepted for publication: 24 September 2012

This work is licensed under a Creative Commons Attribution NonCommercial 3.0 License (CC BYNC 3.0).

(C) Copyright I. Hmamouchi et al., 2013

Licensee PAGEPress, Italy

Rheumatology Reports 2013; 5:e3

doi:10.4081/rr.2013.e3

Exclusion criteria for the study were: concomitant presence of inflammatory bowel disease, chronic renal or hepatic disease, diabetes mellitus, parathyroid or thyroid disease, recent fractures, malnutrition, or taking medications in the past two years known to influence bone metabolism such as vitamin $\mathrm{D}$, calcium and bisphosphonate.

\section{Data collection and measurements}

Demographic and clinical variables were recorded by anamnesis and clinical examination. In order to determine the level of disease activity, Bath Ankylosing Spondylitis Disease Activity Index (BASDAI) was used.22 Physical function was assessed using Bath Ankylosing Spondylitis Functional Index (BASFI; on a scale of $0-10) .23$ The validity and reliability of the Moroccan versions of these forms have been approved. ${ }^{24}$ 


\section{Anthropometric data}

Weight and height were measured without clothes or shoes at the time of bone densitometry measurements. The body mass index (BMI) was calculated as body weight/height $\left(\mathrm{kg} / \mathrm{m}^{2}\right)$.

\section{Physical performance measures}

The short form of the international physical activity questionnaire (IPAQ) was used to evaluate physical performance. The items of IPAQ were structured to provide separate scores on walking, moderate intensity and vigorous intensity activity. Computation of total score requires summation of the duration (in minutes) and frequency (days) of walking, moderate intensity and vigorous intensity activities..$^{25}$

\section{Dietary calcium questionnaire}

Dietary calcium intake was assessed with the frequential self-questionnaire of Faredellone, ${ }^{26}$ which has been modified, simplified and adjusted to the Morrocan food habits.

\section{Biochemical measurements}

Laboratory assessment included C-reactive protein (CRP), alkaline Phosphatise, serum levels of calcium, phosphor, 25-0H vitamin D and parathormon (PTH). DiaSorin 25(OH)D 125I radioimmunoassay kit was used for quantitative determination of $25(\mathrm{OH}) \mathrm{D}$ in plasma or serum. The intra-and interassay CV were 5 and $11 \%$, respectively and the normal range was 30-60 ng/mL. Immunoassay Elecsys PTH Test System was used for quantitative determination of intact PTH in plasma or serum. Intra-and interassay variances were 5 and $7 \%$ and the normal range was $15-65 \mathrm{pg} / \mathrm{mL}$. Vitamin D deficiency was defined as $25(\mathrm{OH}) \mathrm{D}$ serum level less than $20 \mathrm{ng} / \mathrm{mL}$, vitamin D insufficiency as $25(\mathrm{OH}) \mathrm{D}$ levels of 20-30 ng/mL and vitamin D sufficiency as levels greater than $30 \mathrm{ng} / \mathrm{mL}^{27}$ We measured $25(\mathrm{OH}) \mathrm{D}$ during summer season which could have been the highest level of 25(0H)D.

\section{Bone mineral density assessments}

Lumbar spine, trochanter, femoral neck and total hip BMD were measured by dual-energy X-ray absorptiometry with a Lunar prodigy densitometer. Daily quality control was carried out by measurement of a Lunar phantom. At the time of the study, phantom measurements showed stable results. The phantom precision expressed as the CV(\%) was 0.07 . Both T and Z scores were obtained. In the T-score calculations, the manufacturer's ranges for European population reference were used because of the absence of a Moroccan database. Osteoporosis was defined as a T-score $<-2.5$, according to the World Health Organisation study group definition. ${ }^{28}$

\section{Statistical analysis}

Statistical analysis was performed with the Windows 13.0 version of SPSS software (SPSS Inc., Chicago, IL, USA). With 70 cases and 140 controls, this study had $80 \%$ power to detect the difference in the prevalence of hypovitaminosis D in AS patients and healthy subjects using a 95\% confidence interval (95\% CI). For the calculation of the target sample size, we have assumed that difference between 25 hydroxyvitamin D levels in AS patients and in controls is $10 \mathrm{ng} / \mathrm{mL}$. Values are expressed mean \pm S.D or percentages. Normality of the data was tested with a onesample Kolmogorov Smirnov test to indicate the appropriateness of parametric testing. With the aim of evaluating the differences between groups, Student's t test for the variables with a normal distribution was used. Proportions were compared between groups by using chi-squared test or Fisher's exact test. While studying the relations between the variables in the patient group, Pearson correlation test was used. Then, we tried to conduct a multivariate analysis to detect the factors associated with the low vitamin D like BMD, disease duration, disease activity, CRP, BMI and physical activity. However, this approach did not result in any relevant association. Finally, we used the correlation between vitamin D levels and BASDAI after adjustment for age, duration of disease, sunlight exposure, and total taking steroids agreement. A P value of $<0.05$ was accepted as statistically significant.

\section{Results}

\section{Vitamin D status, clinical, and laboratory characteristics of patients with ankylosing spondylitis and controls}

The clinical and laboratory characteristics of patients with $\mathrm{AS}$ and controls are summarised in Table 1.

The mean age of patients was $40 \pm 12$ years old and the mean age of the control group was $42 \pm 11$ years old. The mean BMI of the patients and control group were respectively $23.1 \pm 4.4$ $\mathrm{kg} / \mathrm{m}^{2}$ and $24 \pm 4.1 \mathrm{~kg} / \mathrm{m}^{2}(\mathrm{P}<0.000)$. In comparison with the control group, AS patients showed significantly increased CRP and a significant reduction in vitamin $\mathrm{D}(\mathrm{P}<0.0001)$. No differences in serum calcium, phosphorus and parathormon were detected between groups.

In patients group, 62 patients (88.6\%) had vitamin D deficiency and only eight of subjects (11.4\%) had concentration of vitamin D > 30 $\mathrm{ng} / \mathrm{mL}$. No patient has shown severe vitamin D deficiency $25(\mathrm{OH}) \mathrm{D}<5 \mathrm{ng} / \mathrm{mL})$.
Bone mineral density values of ankylosing spondylitis patients and controls

The lumbar spine BMD, femoral neck BMD, trochanter BMD and total hip BMD were significantly lower in men with AS compared to controls $(\mathrm{P}<0.0001$; Table 2$)$.

According to the WHO classification, 35 patients (50\%) were osteoporotic and 16 (22.9\%) were osteopenia (compared to controls $\mathrm{P}<0.0001$ ).

\section{Correlations between bone mineral density values, biochemical and clinical assessments}

In AS patients, the serum level of vitamin D was negatively correlated with BASFI, serum calcium and PTH $(\mathrm{r}=-0.22, \mathrm{P}<0.05 ; \mathrm{r}=-0.32$, $\mathrm{P}<0.001$, and $\mathrm{r}=-0.41, \mathrm{P}<0.001$; respectively). Disease duration was not correlated with clinical parameters, BMD or biochemical assessments (data not shown, all P>0.05). CRP was negatively correlated with PTH $(r=-0.25$, $\mathrm{P}<0.05)$. BASFI was positively correlated with CRP and ESR $(r=0.39, \mathrm{P}<0.05$ and $\mathrm{r}=0.36$, $\mathrm{P}<0.05$; respectively).

A negative correlation was found between lumbar spine, BASDAI and BASFI $(\mathrm{P}<0.001)$. We found positive correlation between BMD at lumbar spine and femoral total and serum vitamin D levels $(r=0.55, P<0.001$ and $r=0.38$, $\mathrm{P}<0.001$, respectively; Figures 1 and 2).

We found no correlation between IPAQ or total calcium intake and parameters of disease activity. Also, We found no correlation between Vitamin D levels and BMD T-scores (data not shown, all $\mathrm{P}>0.05$ ) (Table 3).

\section{Correlation between vitamin $D$ levels and Bath Ankylosing Spondylitis Disease Activity Index after adjustment for confounding variables}

Vitamin D was negatively correlated to BASDAI without any changes after adjustment for age, duration of disease, sunlight exposure, and total taking steroids $(\mathrm{r}=-0.32, \mathrm{P}<0.001)$ (Figure 3).

\section{Discussion}

In our study, 62 male AS patients (88.6\%) had Vitamin D deficiency, and 35 patients (50\%) were osteoporotic. Vitamin D was negatively correlated to BASDAI without any changes after adjustment for age, duration of disease, sunlight exposure, and total taking steroids.

We found that male AS patients had a lower 
lumbar spine and total hip BMD than controls. According with our results, previous studies have documented osteoporosis in AS.,11,29-32 Thirty-five patients were osteoporotic. These data are consistent with previous reported prevalence of osteoporosis in AS patients that vary from $18.7 \%$ to $62 \% .^{11,30,33}$ The ethology of osteoporosis in AS has not been completely clarified and in various studies, it was suggest- ed that different mechanisms such as immobilization caused by pain and spinal restriction, daily physical activity, inflammatory cytokines, genetic factors, glucocorticoids used for treatment, and NSAIDs have played a role. ${ }^{4-5,34}$

Longitudinal studies had demonstrated a clear relationship between bone loss and markers of disease activity in AS. ${ }^{5,9-11,35}$ In our study, we find correlations between femoral

Table 1. The demographic and laboratory parameters of ankylosing spondylitis patients and controls.

\begin{tabular}{lccc} 
& $\begin{array}{c}\text { AS patients } \\
(\mathrm{n}=70)\end{array}$ & $\begin{array}{c}\text { Controls } \\
(\mathrm{n}=140)\end{array}$ & P \\
Age (years) & $40 \pm 12$ & $42 \pm 11$ & 0.21 \\
Body mass index & $23.1 \pm 4.4$ & $24.8 \pm 4.1$ & 0.008 \\
\hline 25 hydroxyvitamin D (ng/mL) & $17.5 \pm 9.7$ & $21.9 \pm 7.7$ & $<0.001$ \\
CRP (mg/L) & $24.1 \pm 19.6$ & $1.6 \pm 1.2$ & $<0.001$ \\
\hline Total calcium (mg/L) & $93.4 \pm 4.9$ & $93.1 \pm 3.6$ & 0.58 \\
Phosphorus (mg/L) & $29.6 \pm 5.1$ & $30.6 \pm 4.1$ & 0.13 \\
\hline Parathormon (pg/mL) & $64.5 \pm 47.6$ & $56.9 \pm 24.3$ & 0.13 \\
Total calcium intake (mg/m $\left.{ }^{2}\right)$ & $589 \pm 232$ & $664 \pm 344$ & 0.09 \\
\hline Total physical activity (min/wk) & $3712 \pm 2648$ & $5182 \pm 4672$ & $<0.001$ \\
Vitamin D deficiency & $62(88.6)$ & $57(40.7)$ & $<0.001$ \\
\hline BASDAI & $4.1 \pm 1.9$ & & \\
BABSFI & $4.5 \pm 2.7$ & & \\
\hline Duration of disease (years) & $12.1 \pm 7.2$ & & \\
\hline AS, & & \\
\hline
\end{tabular}

AS, ankylosing spondylitis; BASDAI, Bath Ankylosing Spondylitis Disease Activity Index; BABSFI, Bath Ankylosing Spondylitis Functional Index.

Table 2. Bone mineral density values of ankylosing spondylitis patients and controls.

\begin{tabular}{lccc} 
& $\begin{array}{c}\text { Ankylosing spondylitis } \\
\text { patients } \\
(\mathrm{n}=70)\end{array}$ & $\begin{array}{c}\text { Controls } \\
(\mathrm{n}=140)\end{array}$ & $\mathrm{P}$ \\
\hline Lumbar spine $\left(\mathrm{g} / \mathrm{cm}^{2}\right)$ & $0.980 \pm 0.301$ & $1.120 \pm 0.148$ & $<0.001$ \\
Femur neck $\left(\mathrm{g} / \mathrm{cm}^{2}\right)$ & $0.990 \pm 0.268$ & $1.195 \pm 0.180$ & $<0.001$ \\
\hline Trochanter $\left(\mathrm{g} / \mathrm{cm}^{2}\right)$ & $0.909 \pm 0.445$ & $0.822 \pm 0.145$ & $<0.001$ \\
Femur total $\left(\mathrm{g} / \mathrm{cm}^{2}\right)$ & $0.862 \pm 0.175$ & $1.038 \pm 0.163$ & $<0.001$ \\
\hline
\end{tabular}

and lumbar BMD and disease activity parameters and serum vitamin D levels. The lack of correlation between BMD and disease duration observed in our cohort agrees with some previous studies and suggests that bone loss occurs early in the disease. ${ }^{35,36}$ However, several other studies found a positive correlation between disease duration and lumbar spine BMD, indicating that overestimation of the lumbar spine BMD (measured by DXA) occurred in patients with advanced AS.5,6,11

In comparison with the control group, male AS patients showed significantly decreased vitamin D. Vitamin D was negatively correlated to BASDAI without any changes after adjustment for age, duration of disease, sunlight exposure, and total taking steroids. Clinical studies have reported the impact of vitamin D in AS as an endogenous immune modulator, suppressing activated $\mathrm{T}$ cells and cell proliferation that may accelerate the inflammation process. ${ }^{14-19}$ In a recent study Lange et al. observed that high disease activity in AS is associated with an alteration in vitamin D metabolism, increased bone resorption and that AS patients with osteoporosis had significantly lower vitamin D levels compared to AS patients with normal BMD. ${ }^{7,11}$ Obermayer $e t$ al. suggested a close association of BMD, bone metabolism, and inflammatory activity with Fok1 polymorphisms of the vitamin D receptor gene in male AS patients..$^{13}$ Also, it was stated that with the lack of vitamin $\mathrm{D}$, which is an endogenous immunomodulator, proliferation of the T cells and activation cannot be prevented and that the severity of inflammatory process may increase. ${ }^{5}$

In our study a surprisingly high incidence of vitamin D deficiency was found in Morrocan patients and controls. Even Morocco is a sunny country where the exposure to sunlight might be considered to be sufficient to keep adequate vitamin D status, vitamin D deficiency is often observed. Previous study has shown that vitamin D deficiency is common among Moroccan

Table 3. Correlations between clinical and biochemical assessments in ankylosing spondylitis patients.

\begin{tabular}{|c|c|c|c|c|c|c|c|c|c|c|}
\hline & 250H D & Age & BASFI & BASDAI & CRP & ESR & $\mathrm{Ca}$ & PTH & IPAQ & BMD L \\
\hline Age & NS & & & & & & & & & \\
\hline BAFI & $-0.22 *$ & $-0.24^{*}$ & & & & & & & & \\
\hline BASDAI & $-0.32 * *$ & NS & $0.62 * *$ & & & & & & & \\
\hline CRP & NS & NS & $0.39 * *$ & NS & & & & & & \\
\hline ESR & NS & NS & $0.36^{*}$ & NS & $0.48^{* *}$ & & & & & \\
\hline $\mathrm{Ca}$ & $-0.41^{* *}$ & NS & $-0.23^{*}$ & NS & $-0.26^{*}$ & NS & & & & \\
\hline PTH & $-0.41^{* *}$ & $-0.29 *$ & NS & NS & $-0.25^{*}$ & NS & NS & & & \\
\hline IPAQ & NS & $-0.24^{*}$ & NS & NS & NS & NS & NS & NS & & \\
\hline BMD LS & $0.31^{* *}$ & NS & $-0.31^{* *}$ & $-0.32 * *$ & NS & NS & NS & NS & NS & \\
\hline BMD F & $0.32^{* *}$ & NS & NS & NS & NS & NS & NS & NS & NS & $0.59^{* *}$ \\
\hline
\end{tabular}

AS, ankylosing spondylitis; 25OH D, 25-hydroxyvitamin D; BASFI, Bath Ankylosing Spondylitis Functional Index; BASDAI, Bath Ankylosing Spondylitis Disease Activity Index; CRP, C-reactive protein; ESR, erythrocyte sedimentation rate; Ca, calcium; PTH, parathormon; BMD, bone mineral density; LS, lumbar spine; F, femoral; NS, no significant. *P<0.05, ${ }^{* *} \mathrm{P}<0.001$. 


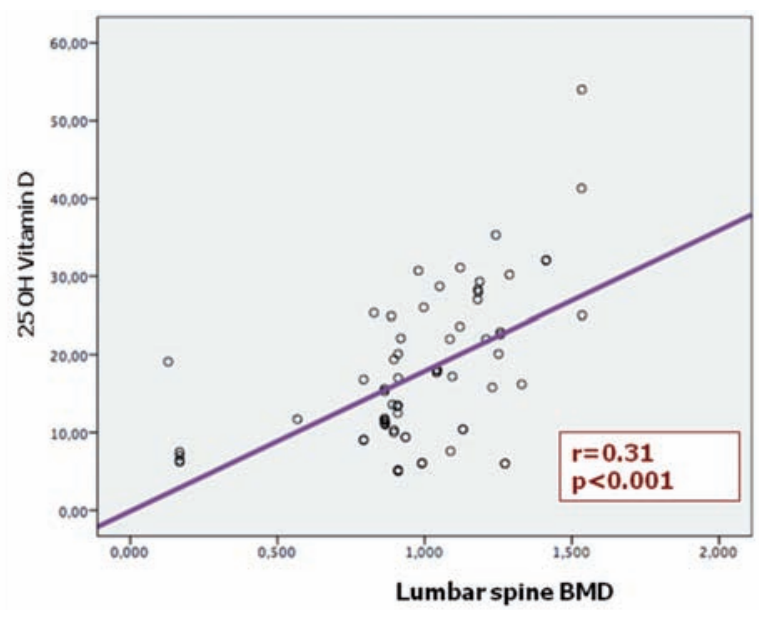

Figure 1. Correlation between serum level of $250 \mathrm{HD}$ and lumbar spine BMD. Serum levels of $25 \mathrm{OHD}$ and lumbar spine BMD are significantly positively correlated in AS patients.

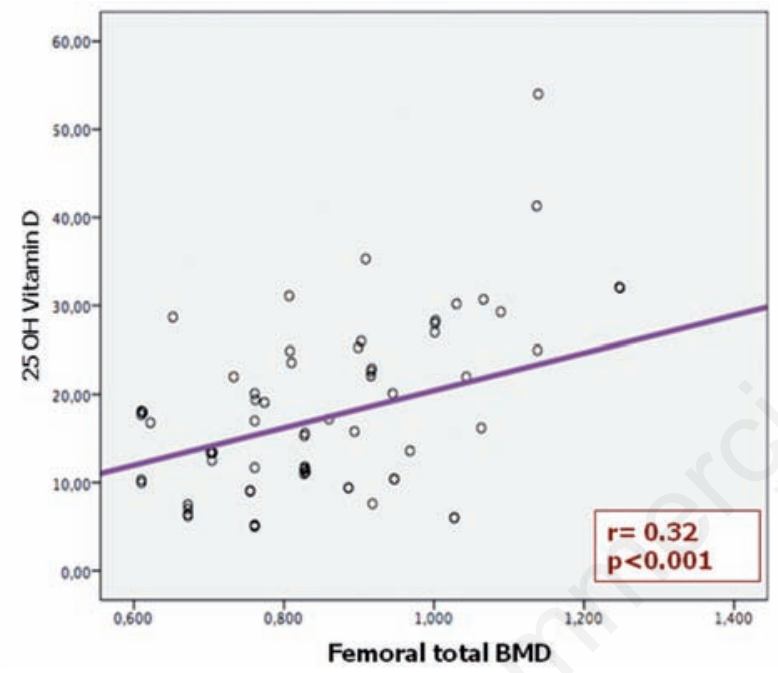

Figure 2. Correlation between serum level of 25OHD and femoral total BMD. Serum level of $25 \mathrm{OHD}$ and femoral total BMD are significantly positively correlated in AS patients.

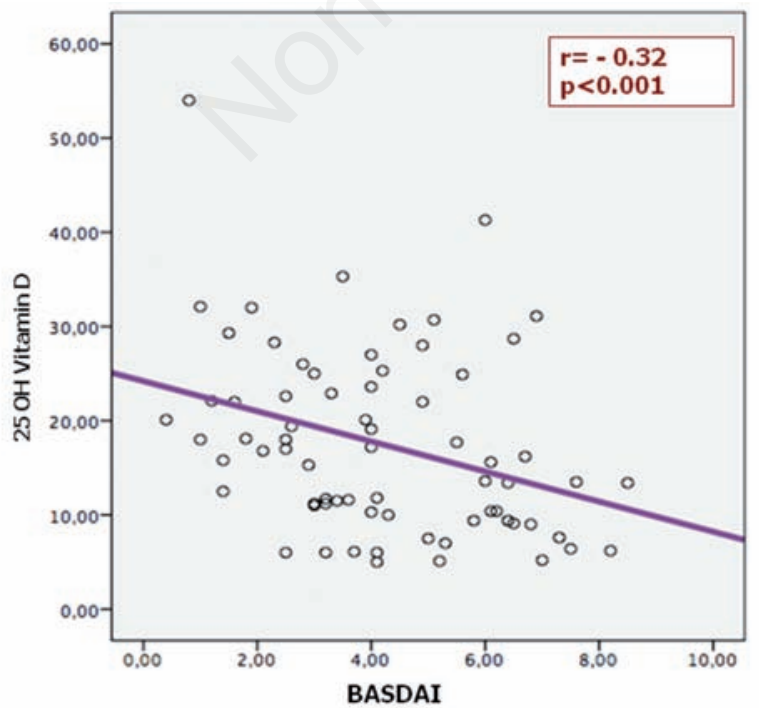

Figure 3. Correlation between serum level of 250HD and BASDAI. Serum level of $25 \mathrm{OHD}$ and femoral total BMD are significantly negatively correlated in AS patients after adjustment for age, duration of disease, sunlight exposure, and total taking steroids. women and this was influenced by a lack of sun exposure and veiled clothing style. ${ }^{37}$ The ethnicity factor was highly correlated with low levels of vitamin D. Another factor of the high incidence of vitamin D deficiency among Arab populations may be a genetic polymorphism of VDRs, an issue that has to be investigated. ${ }^{38}$

Our study had few limitations and a number of strengths. First, BMD was monitored with dual-energy x-ray absorptiometry (DXA). However, previous studies have shown that the lumbar spine BMD in AS can be overestimated by the presence of syndesmophytes, ligament calcifications, and fusion of facet joints. . $^{3940}$ Currently, quantitative computed tomography (QCT) is considered to be the best technique to measure spinal BMD in patients with advanced AS. ${ }^{5}$ However, QCT is expensive and has a high radiation dose compared to DXA.41 Therefore, an alternative method to monitor bone loss in AS patients is desirable.

Second, it would be useful if blood samples were collected at different times of the year to study the seasonal variation of vitamin D serum level. Also, vitamin D metabolism may be influenced by age. However, we found significantly lower vitamin D levels in AS patients compared with age-matched controls. In addition, we found no significant correlation between age and vitamin D serum levels.

Also, The IPAQ questionnaire has not been validated for use in AS. But The IPAQ has reasonable measurement properties for monitoring population levels of physical activity among 18- to 65-yr-old adults in diverse settings. The short IPAQ form last $7 d$ recall is recommended for national monitoring and the long form for research requiring more detailed assessment. ${ }^{25}$

\section{Conclusions}

We found a high incidence of vitamin D deficiency in our patients. Our study suggests that vitamin D deficiency in male AS may indirectly lead to osteoporosis by causing an increase in the inflammatory activity. Monitoring vitamin D levels would be useful in order to determine the patients under osteoporosis risk.

\section{References}

1. Van Der Linden S, Van Der Hejide D, Braun J, Budd RC, et al. Ankylosing spondylitis. In: Harris Ed. Kelley's textbook of rheumatology. Philadelphia: Elsevier Saunders; 2005. pp 1125-1141.

2. Franck H, Meurer T, Hofbauer LC. Evaluation of bone mineral density, hormones, biochemical markers of bone 
metabolism metabolism, and osteoprotegerin serum levels in patients with ankylosing spondylitis. J Rheumatol 2004;31: 2236-41.

3. Ghozlani I, Ghazi M, Nouijai A, et al. Prevalence and risk factors of osteoporosis and vertebral fractures in patients with ankylosing spondylitis. Bone 2009;44:7726.

4. Gratacos J, Collado A, Pons F, et al. Significant loss of bone mass in patients with early, active ankylosing spondylitis: a follow up study. Arthritis Rheum 1999;42: 2319-24.

5. Lange U, Teichmann J, Strunk J, et al. Association of 1.25 vitamin D3 deficiency, disease activity and low bone mass in ankylosing spondylitis. Osteoporos Int 2005;16:1999-2004.

6. Maillefert JF, Aho LS, El Maghraoui A, et al. Changes in bone density in patients with ankylosing spondylitis: a two-year followup study. Osteoporos Int 2001;12:605-9.

7. Toussirot E, Ricard-Blum S, Dumoulin G, et al. Relationship between urinary pyridinium cross-links, disease activity and disease subsets of ankylosing spondylitis. Rheumatology 1999;38:21-7.

8. El Maghraoui A. Osteoporosis and ankylosing spondylitis. Joint Bone Spine 2004;71: 291-5.

9. Mermerci Ba kan B, Pekin Do an Y, Sivas $\mathrm{F}$, et al. The relation between osteoporosis and vitamin D levels and disease activity in ankylosing spondylitis. Rheumatol Int 2010;30:375-81.

10. Arends S, Spoorenberg A, Bruyn GA, et al. The relation between bone mineral density, bone turnover markers, and vitamin D status in ankylosing spondylitis patients with active disease: a cross-sectional analysis. 0steoporos Int 2011;22:1431-9.

11. Lange U, Jung 0, Teichmann J, et al. Relationship between disease activity and serum levels of vitamin D metabolites and parathyroid hormone in ankylosing spondylitis. Osteoporos Int 2001;12:1031-5.

12. Mermerci Baskan B, Pekin Dogan Y, Sivas F, et al. The relation between osteoporosis and vitamin D levels and disease activity in ankylosing spondylitis. Rheumatol Int 2010;30:375-81.

13. Obermayer-Pietsch BM, Lange U, Tauber G, et al. Vitamin D receptor initiation codon polymorphism, bone density and inflammatory activity of patients with ankylosing spondylitis. Osteoporos Int 2003;14:995-1000.

14. Baier R, Grauer A, Lazaretti-Castro M, et al. Differential effects of 1,25-dihydroxyvitamin D3 on cell proliferation and calci- tonin gene expression. Endocrinology 1994;135:2006-11.

15. Muller K, Bendtzen K. 1,25-Dihydroxyvitamin D3 as a natural regulator of human immune functions. J Investig Dermatol Symp Proc 1996;1:68-71.

16. Amento EP. Vitamin D and the immune system. Steroids 1987;49:55-72.

17. Bouillon R, Okamura WH, Norman AW. Structure-function relationships in the vitamin D endocrine system. Endocr Rev 1995;16:200-57.

18. Cantorna MT, Mahon BD. D-hormone and the immune system. J Rheumatol 2005;76: 11-20.

19. Deluca HF, Cantorna MT. Vitamin D: its role and uses in immunology. Faseb $\mathrm{J}$ 2001;15:2579-85.

20. Overbergh L, Decallonne B, Valckx D, et al. Identification and immune regulation of 25-hydroxyvitamin D-1-alphahydroxylase in murine macrophages. Clin Exp Immunol 1998;120:139-46.

21. Van der Linden S, Valkenburg HA, Cats A. Evaluation of diagnostic criteria for ankylosing spondylitis. A proposal for modification of the New York criteria. Arthritis Rheum 1984;27:361-8.

22. Garrett S, Jenkinson T, Kennedy LG et al. A new approach to defining disease status in ankylosing spondylitis: the Bath Ankylosing Spondylitis Disease Activity Index. J Rheumatol 1994;21:2286-91.

23. Calin A, Garrett S, Whitelock H, et al. A new approach to defining functional ability in ankylosing spondylitis: the development of the Bath Ankylosing Spondylitis Functional Index. J Rheumatol 1994;21: 2281-5.

24. Rostom S, Benbouaaza K, Amine B, et al. Psychometric evaluation of the Moroccan version of the Bath Ankylosing Spondylitis Functional Index (BASFI) and Bath Ankylosing Spondylitis Disease Activity Index (BASDAI) for use in patients with ankylosing spondylitis. Clin Rheumatol 2010;29:781-8.

25. Craig CL, Marshall AJ, Sjöström M, et al. International Physical Activity Questionnaire: 12-country reliability and validity. Med Sci Sports Exerc 2003; 35:1381-95.

26. Fardellone P, Sebert JL, Bouraya M, et al. Evaluation of the calcium content of diet by frequential self-questionnaire. Rev Rhum Mal Osteoartic 1991;58:99-103.

27. Heaney RP. Functional indices of vitamin D status and ramification of vitamin D deficiency. Am J Clin Nutr 2004;80:1706S$1709 \mathrm{~S}$.

28. Worlds Health Organisation Study Group. Assessment of fracture risk and its appli- cation to screening for post-menopausal osteoporosis. In WHO Technical Report Series, No.843 Geneva: WHO; 1994.

29. Will R, Palmer R, Bhalla AK, et al. Osteoporosis in early ankylosing spondylitis: a primary pathological event? Lancet 1989;2:1483-5.

30. El Maghraoui A, Borderie D, Cherruau B, et al. Osteoporosis, body composition, and bone turnover in ankylosing spondylitis. $\mathrm{J}$ Rheumatol 1989;26:2205-9.

31. Ralston SH, Urquhart GD, Brzeski M, et al. Prevalence of vertebral compression fractures due to osteoporosis in ankylosing spondylitis. BMJ 1990; 300:563-5.

32. Mullaji AB, Upadhyay SS, Ho EK. Bone mineral density in ankylosing spondylitis DEXA comparison of control subjects with mild and advanced cases. J Bone Joint Surg Br 1994;76:660-5.

33. Hanson CA, Shagrin JW, Duncan H. Vertebral osteoporosis in ankylosing spondylitis. Clin Orthop Relat Res 1971;74: 59-64.

34. Gratacos J, Collado A, Filella X, et al. Serum cytokines (IL-6, TNF-alpha, IL-1 beta and IFN-gamma) in ankylosing spondylitis: a close correlation between serum IL-6 and disease activity and severity. Br J Rheumatol 1994;33:927-31.

35. Muntean L, Rojas-Vargas M, Font P, et al. Relative value of the lumbar spine and hip bone mineral density and bone turnover markers in men with ankylosing spondylitis. Clin Rheumatol 2001;30:691-5.

36. Toussirot E, Michel F, Wendling D. Bone density, ultrasound measurements and body composition in early ankylosing spondylitis. J Rheumatol 2001;40:882-8.

37. Allali F, El Aichaoui S, Khazani H, et al. High prevalence ofhypovitaminosis D in Morocco: relationship to lifestyle, physical performance, bone markers, and bone mineral density. Semin Arthritis Rheum 2009;38:444-51.

38. Braun-Moscovici Y, Toledano K, Markovits $\mathrm{D}$, et al. Vitamin D level: is it related to disease activity in inflammatory joint disease? Rheumatol Int 2011;31:493-9.

39. Baek HJ, Kang SW, Lee YJ, et al. Osteopenia in men with mild and severe ankylosing spondylitis. Rheumatol Int 2005;26:30-4.

40. Lee YS, Schlotzhauer T, Ott SM, et al. Skeletal status of men with early and late ankylosing spondylitis. Am J Med 1997; 103:233-41.

41. Bessant R, Keat A. How should clinicians manage osteoporosis in ankylosing spondylitis? J Rheumatol 2002;29:1511-9. 